\title{
The fate of nonaortic arterial segments in Marfan patients
}

\author{
Florian S. Schoenhoff, MD, Murat Yildiz, MD, Bettina Langhammer, MD, Silvan Jungi, MD, \\ Thomas R. Wyss, MD, Vladimir Makaloski, MD, Juerg Schmidli, MD, and Thierry Carrel, MD
}

\section{ABSTRACT}

Objectives: The aim of this study was to investigate the fate of nonaortic arterial segments in patients with Marfan syndrome (MFS).

Methods: This was a retrospective analysis of 100 consecutive patients with MFS fulfilling Ghent criteria who underwent 192 interventions on any segment of the arterial tree and were followed over the past 20 years. A review of the available imaging regarding 9 defined regions of interest of the carotid, innominate, subclavian, iliac, and femoral arteries was performed.

Results: Mean follow-up interval was $11.6 \pm 7.7$ years. Of 600 measurements that were performed, $414(69 \%)$ arterial segments showed dilatation above the upper range of normal. There were no significant sex differences. In 100 patients, 66 dissections in nonaortic arterial segments in 33 patients were identified. Nineteen patients with or without previous dissection underwent 34 interventions. Most interventions were performed on the iliac arteries (56\%), followed by the subclavian arteries $(21 \%)$, the intercostal arteries $(9 \%)$, the carotid arteries $(6 \%)$, the visceral arteries $(6 \%)$, and the innominate artery $(3 \%)$. Most iliac artery interventions ( $88 \%$ ) were caused by dilatations due to previous dissections, whereas this was only the case in $17 \%$ of interventions on the subclavian arteries.

Conclusions: Most patients with MFS presented with at least 2 dilated nonaortic arterial segments. The current data suggest that $20 \%$ of MFS patients will need some form of intervention on nonaortic arterial segments 5 to 6 years after their first aortic intervention, referring to the first aortic dissection of the patient if the patient had a history of dissection. Routine long-term follow-up imaging should include the iliac arteries as well as the supra-aortic branches. (J Thorac

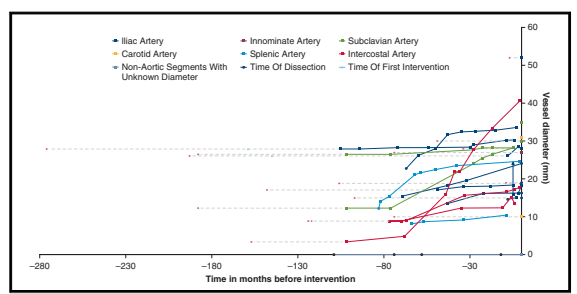

Diameter increase of nonaortic arterial segments over time before intervention

\section{Central Message}

The current data suggest that $20 \%$ of MFS patients will need some form of intervention on nonaortic arterial segments 5 to 6 years after their first aortic intervention, referring to the first aortic dissection of the patient if the patient had a history of dissection.

\section{Perspective}

Routine long-term follow-up imaging should include the iliac arteries as well as the supra-aortic branches. We recommend annual follow-up when the diameter of a nonaortic arterial segment has reached a diameter of $2.0 \mathrm{~cm}$.

See Commentary on page 2157. Cardiovasc Surg 2019;157:2150-6)

Marfan syndrome (MFS) is an autosomal dominant disorder caused by mutations in the gene encoding for the extracellular matrix protein fibrillin- $1 .^{1-3}$ Patients with MFS exhibit skeletal, ocular, and cardiovascular manifestations. Acute aortic dissection due to aortic aneurysms still determines morbidity and mortality in patients with MFS. Although there has been a well documented shift toward more interventions on the distal aorta as more and more patients undergo elective root

From the Department of Cardiovascular Surgery, University Hospital Bern, Bern, Switzerland.

Drs Schoenhoff and Yildiz contributed equally to this work.

Received for publication May 15, 2018; revisions received Oct 3, 2018; accepted for publication Oct 19, 2018; available ahead of print Dec 18, 2018.

Address for reprints: Florian S. Schoenhoff, MD, Department of Cardiovascular Surgery, University Hospital Bern, 3010 Bern, Switzerland (E-mail: florian. schoenhoff@insel.ch).

$0022-5223 / \$ 36.00$

Copyright (c) 2018 by The American Association for Thoracic Surgery

https://doi.org/10.1016/j.jtcvs.2018.10.089 repair, little is known regarding the incidence and clinical relevance of nonaortic arterial aneurysms in patients with MFS. ${ }^{1}$ The aim of the current study was to evaluate absolute diameters, incidence of aneurysms and dissections, as well as the need for interventions in nonaortic arterial segments in patients with MFS.

\section{METHODS}

We retrospectively analyzed 100 patients with MFS (mean age at last follow-up, $48.3 \pm 15.7$ years, $54 \%$ male) fulfilling the revised Ghent criteria $^{4}$ who underwent 158 thoracic, thoracoabdominal, or abdominal aortic interventions as well as 34 interventions on nonaortic arterial segments since January 1995 until January 2016. Mean age at first aortic intervention was $35.6 \pm 1.4$ years and mean follow-up was

- Scanning this $\mathrm{QR}$ code will take you to the article title page to access supplementary information.

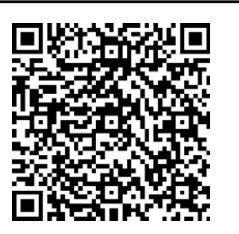




\section{Abbreviations and Acronyms \\ $\mathrm{CT}=$ computed tomography \\ MFS $=$ Marfan syndrome}

$11.6 \pm 7.7$ years (Figure 1 and Table 1 ). In the current patient population, 19 patients of 9 families were first-degree relatives. There was no other family relationship.

Patients were actively followed-up in our MFS clinics. Patients received thoracoabdominal imaging at least 3, 6, and 12 months after any clinical event (dissection, surgery) and then depending on the findings. Additionally, a phone interview was conducted according to a standardized questionnaire that was sent to the patients in advance. Individual informed consent was obtained and patients were asked if we were allowed to contact their primary care provider regarding recent developments, changes in medications, or computed tomography (CT) scans that have been performed outside our institution. Hereby, a $99 \%$ completeness of follow-up was achieved. Evaluation and standard measurements of 9 regions of interest (carotid, subclavian, iliac, and femoral arteries as well as the innominate artery) were performed for clinical routine follow-up using contrast-enhanced $\mathrm{CT}$ scanning or magnetic resonance imaging.

For the purpose of this study, the largest, most recent, or preinterventional diameter for each segment was used as the patient-specific diameter. There are limited data regarding the normal distribution of diameters of nonaortic arteries in the general population. For the purpose of this study we used reference values as given by Johnston and colleagues from the Subcommittee on Reporting Standards for Arterial Aneurysms from the Society of Vascular Surgery. ${ }^{5}$ Because this publication did not include reference values for the subclavian artery we used reference values from Peripheral Vascular Ultrasound by Thrush and colleagues. ${ }^{6}$ Reference values were as follows: common carotid artery 6.3 to $8.4 \pm 1.0$ to $1.4 \mathrm{~mm}$ for men and $7.7 \pm 0.8 \mathrm{~mm}$ for women, subclavian artery 6 to $11 \mathrm{~mm}$, iliac artery 11.7 to $12.3 \pm 2 \mathrm{~mm}$ for men, 9.7 to $10.2 \pm 1.5$ to $1.9 \mathrm{~mm}$ for women, femoral artery 7.8 to $11.2 \pm 0.9$ to $3 \mathrm{~mm}$ for men and 7.8 to $8.5 \pm 0.7$ to $1.1 \mathrm{~mm}$ for women. ${ }^{5,6}$

In case a range of mean diameters or a range of standard deviations was given, the respective average diameter was calculated and 2 standard deviations were added. For the purpose of this study, the following values were considered as comparative values: common carotid artery $\geq 10 \mathrm{~mm}$ for men, $\geq 9 \mathrm{~mm}$ for women, subclavian artery $\geq 11 \mathrm{~mm}$, iliac artery $\geq 16 \mathrm{~mm}$ for men, $\geq 13 \mathrm{~mm}$ for women, femoral artery $\geq 13 \mathrm{~mm}$ for men, and $\geq 10 \mathrm{~mm}$ for women (Table 2). All arterial segments with diameters above these thresholds were considered "dilated," even if an aneurysm was already present.

Of the possible 900 measurements in 100 patients who were supposed to be evaluated, data from 682 points of interest could be obtained. This corresponds to a $76 \%$ completeness of acquired measurements. Reasons for not obtaining reliable measurements were mostly because of the femoral vessels not being included in the imaging. All points of interest (ie, arterial segments) could be assessed in 65 of 100 patients.

\section{Statistical Analysis}

Values are given in mean \pm standard deviation, when appropriate. Comparisons between groups were performed using Pearson $\chi^{2}$ test for dichotomous variables and Student $t$ test for continuous variables. Analysis was performed with Stata version 13 software (StataCorp, College Station, Tex).

\section{RESULTS}

\section{Diameters of Nonaortic Arterial Segments}

Of 600 measurements (excluding the 82 measurements of the innominate artery) that were performed, $276(46 \%)$

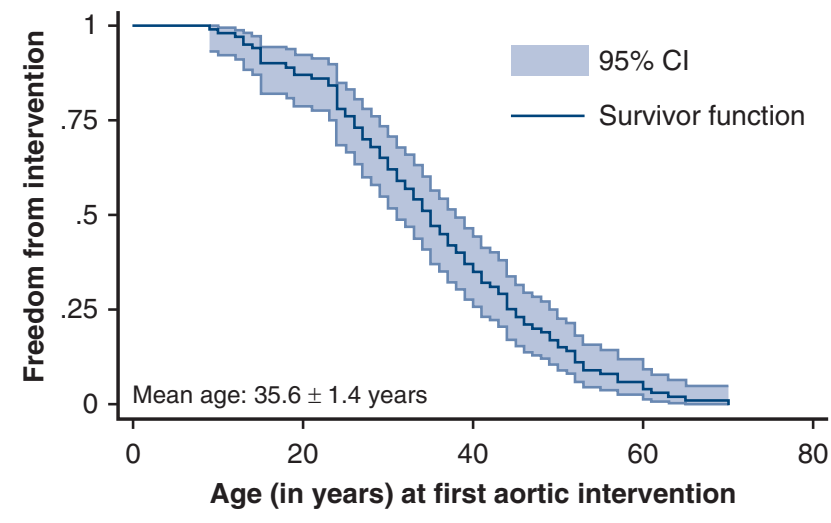

Number at risk

$\begin{array}{lllll}100 & 87 & 37 & 6 & 0\end{array}$

FIGURE 1. Kaplan-Meier graph depicting age at first aortic intervention in patients with Marfan syndrome. $C I$, Confidence interval.

arterial segments were dilated according to the definition previously mentioned. Only 1 of the 65 evaluated patients with a complete data set showed no enlargement in nonaortic arterial segments. All other patients had at least 2 or more arterial segments that were dilated. Mean diameters of nonaortic arterial segments and percentages of diameters above comparative values are shown in Tables 2 and 3. There were no significant sex differences regarding right carotid $(P=.14)$, left carotid $(P=.35)$, right subclavian $(P=.22)$, left subclavian $(P=.64)$, innominate $(P=.4)$, right iliac $(P=.45)$, left iliac $(P=.25)$, right femoral $(P=.53)$, or left femoral artery $(P=.3)$ diameters.

\section{Dissections in Aortic and Nonaortic Arterial Segments}

Of 100 patients, 29 suffered from Stanford type A and 26 from type B dissection. Three of those patients who initially presented with type B dissection later suffered from type A dissection and 4 patients with type A dissection developed an unrelated type B dissection during follow-up. Of those 48 patients (with 55 events) with aortic dissection, 33 patients $(69 \%)$ had 66 related and/or unrelated dissections in nonaortic arterial segments.

Most aortic dissections affected the iliac arteries (40/66; $61 \%)$, followed by the subclavian arteries $(12 / 66 ; 18 \%)$, the innominate artery $(7 / 66 ; 11 \%)$, the carotid arteries $(5 / 66 ; 8 \%)$, and the femoral arteries $(2 / 66 ; 3 \%)$. Although most dissections in nonaortic arterial segments remained asymptomatic, $21 / 66(32 \%)$ of the affected arterial segments needed intervention during follow-up (Table 4).

\section{Interventions}

During follow-up, 34 interventions in nonaortic arterial segments were performed in 19 patients. Most interventions were performed on the iliac arteries $(19 / 34 ; 56 \%)$, followed by the subclavian arteries $(7 / 34 ; 21 \%)$, the intercostal 
TABLE 1. Baseline characteristics of our study population

\begin{tabular}{lc}
\hline \multicolumn{1}{c}{ Characteristic } & Value \\
\hline Age, y & $48.3 \pm 15.7$ \\
Male sex & $54(54)$ \\
\hline Follow-up, y & $11.6 \pm 7.7$ \\
Age at first aortic intervention, y & $35.6 \pm 1.4$ \\
Diabetes mellitus & $3(3)$ \\
Arterial hypertension & $31(31)$ \\
Dyslipidemia & $24(24)$ \\
Smoking & $24(24)$ \\
Mean age at first nonaortic arterial intervention, y & $42.8 \pm 2.2$ \\
Initially presenting with dissection & \\
Stanford type A & $26(26)$ \\
Stanford type B & $10(10)$ \\
Dissection initially or during follow-up & \\
Stanford type A & $29(29)$ \\
Stanford type B & $26(26)$ \\
First aortic intervention & \\
Valve-sparing root replacement & $27(27)$ \\
Bentall procedure or aortic valve replacement & $54(54)$ \\
Ascending aortic or aortic arch replacement & $13(13)$ \\
Descending aortic replacement & $4(4)$ \\
TAAAR & $2(2)$ \\
EVAR/TEVAR & $0(0)$ \\
All aortic interventions & $29(18)$ \\
Valve-sparing root replacement & $65(41)$ \\
Bentall procedure or aortic valve replacement & $27(17)$ \\
Ascending aortic or arch replacement & $15(10)$ \\
Descending aortic replacement & $17(11)$ \\
TAAAR & $5(3)$ \\
EVAR/TEVAR & \\
\hline Date presed & \\
\hline
\end{tabular}

Data are presented as mean \pm standard deviation or $\mathrm{n}(\%)$. TAAAR, Thoracoabdominal aortic aneurysm repair; EVAR, endovascular aortic repair; TEVAR, thoracic endovascular aortic repair.

arteries $(3 / 34 ; 9 \%)$, the carotid arteries $(2 / 34 ; 6 \%)$, the visceral arteries $(2 / 34 ; 6 \%)$, and the innominate artery $(1 / 34 ; 3 \%)$, whereas 4 interventions were reinterventions on the same segment (Table 5).

The mean age of the patients at the time of interventions on nonaortic arterial segments was $42.8 \pm 2.2$ years (Figure 2). Most patients with iliac artery interventions $(14 / 16 ; 88 \%)$ underwent surgery because of dilatations after previous dissections (7 patients with type $\mathrm{A}$ and 7 with type B dissections). The remaining 2 patients also suffered from type A dissection but it was unclear whether that was the cause of the dilatation. In the entire cohort of patients with iliac artery dissection, $48 \%$ of dissected iliac arteries needed some form of intervention during follow-up. Three patients in this group underwent reinterventions on the iliac arteries because of progressive dilatation.

Interventions on the subclavian arteries comprise the second largest groups of interventions. Four patients underwent 7 subclavian artery interventions but in contrast to the iliac arteries, $86 \%(6 / 7)$ of patients did not suffer from previous dissection. One patient underwent reintervention because of malperfusion.

Mean time between first aortic intervention and subsequent interventions on nonaortic arterial segments was $6.1 \pm 1.1$ years. In patients with a history of dissection, interventions on nonaortic arterial segments were performed on average $5.1 \pm 1.2$ years after the event (Figures 3 and 4).

Aneurysms of the intercostal arteries are rare in general as well as in patients with MFS. We saw 1 patient who presented with several large (up to $41 \mathrm{~mm}$ ) intercostal artery aneurysms and underwent 3 coilings. Two carotid artery interventions were performed; 1 on a patient with a symptomatic internal carotid aneurysm without previous dissection and 1 during aortic repair for acute type A dissection. Two patients developed splenic artery aneurysms, which were subsequently coiled. One patient underwent surgery of a symptomatic aneurysm of the innominate artery, whereas both subclavian arteries were addressed during the same intervention as well.

Of 48 patients who presented with type A or type B dissection initially or during follow-up, $35 \%$ (17 patients; 6 type A, 7 type B, 3 type A followed by type B, and 1 type B followed by type A) had an intervention on a nonaortic arterial segment. In comparison, only $4 \%$ of patients without history of acute aortic dissection underwent interventions on nonaortic arterial segments $(P<.0001)$. Mean time between type A dissection and intervention was $6.9 \pm 1.6$ years, and $6.5 \pm 1.5$ years for type $\mathrm{B}$ dissection. The growth of nonaortic arterial segments in patients who eventually underwent some form of intervention is depicted in detail in Figure 5 and Video 1.

\section{DISCUSSION}

The widespread use of prophylactic root repair has led to profound changes in the long-term survival of MFS patients. The past decades saw a significant increase in survival in patients suffering from type A dissection because of technical advances such as selective antegrade cerebral perfusion but also aggressive treatment of perioperative malperfusion. As a result, the number of patients who presented for follow-up after complex repair is steadily increasing. ${ }^{7,8}$

Surgery in MFS patients has moved away from just being life-saving surgery toward elective repair of almost every segment of the arterial tree. Because of the complex nature of the vascular problems we now face, there is surprisingly little known regarding the incidence and relevance of nonaortic arterial aneurysms in MFS patients. Although we frequently observed dilation of nonaortic arterial segments in routine imaging, we suspect that interventions are rarely necessary. 
TABLE 2. Mean diameters of nonaortic arterial segments with comparative values

\begin{tabular}{|c|c|c|c|c|}
\hline Nonaortic arterial segment & All & Men & Women & Comparative values \\
\hline Innominate artery & $15.8 \pm 0.7$ & $15.3 \pm 0.6$ & $16.3 \pm 1.1$ & - \\
\hline Right carotid artery & $8.4 \pm 0.2$ & $8.2 \pm 0.2$ & $8.6 \pm 0.4$ & $\begin{array}{c}\text { Men } \geq 10 \\
\text { Women } \geq 9\end{array}$ \\
\hline Left carotid artery & $8.7 \pm 0.2$ & $8.8 \pm 0.2$ & $8.5 \pm 0.2$ & $\begin{array}{c}\text { Men } \geq 10 \\
\text { Women } \geq 9\end{array}$ \\
\hline Right subclavian artery & $13.1 \pm 0.6$ & $13.8 \pm 0.8$ & $12.2 \pm 0.7$ & $\begin{array}{c}\text { Men }>11 \\
\text { Women }>11\end{array}$ \\
\hline Left subclavian artery & $12.4 \pm 0.8$ & $12.9 \pm 1.1$ & $11.8 \pm 0.7$ & $\begin{array}{c}\text { Men }>11 \\
\text { Women }>11\end{array}$ \\
\hline Right iliac artery & $16.2 \pm 0.9$ & $17.6 \pm 1.3$ & $14.7 \pm 1.2$ & $\begin{array}{c}\text { Men } \geq 16 \\
\text { Women } \geq 13\end{array}$ \\
\hline Left iliac artery & $17.6 \pm 1.0$ & $18.5 \pm 1.2$ & $16.6 \pm 1.5$ & $\begin{array}{c}\text { Men } \geq 16 \\
\text { Women } \geq 13\end{array}$ \\
\hline Right femoral artery & $12.0 \pm 0.3$ & $13.1 \pm 0.4$ & $10.8 \pm 0.3$ & $\begin{array}{c}\text { Men } \geq 13 \\
\text { Women } \geq 10\end{array}$ \\
\hline Left femoral artery & $12.2 \pm 0.3$ & $13.2 \pm 0.4$ & $11.0 \pm 0.4$ & $\begin{array}{c}\text { Men } \geq 13 \\
\text { Women } \geq 10\end{array}$ \\
\hline
\end{tabular}

Values are in millimeters.

There are very few data on size of peripheral arteries in healthy individuals, let alone detailed values that would allow calculating standard deviations or accounting for age or different body surface areas. We used reference values as given by Johnston and colleagues from the Subcommittee on Reporting Standards for Arterial Aneurysms from the Society of Vascular Surgery. ${ }^{5}$ These data are from a pooled collection of different assessment methods (CT, ultrasound, etc). The article was published in 1991 but still remains the most comprehensive publication on this topic.

The current study comprised all patients who underwent any aortic intervention during the past 20 years. Although follow-up is excellent, our population is certainly enriched regarding the number of patients with a history of dissection because all patients already underwent some form of intervention. In the current study, most patients had at least 2 dilated nonaortic arterial segments, whereas most interventions occurred on the level of the iliac arteries after dissection. In our patient population, $57 \%$ of patients with iliac artery dissection had to undergo interventions on the

TABLE 3. Numbers and percentages of nonaortic arterial segments above comparative values

\begin{tabular}{lccc}
\hline $\begin{array}{c}\text { Nonaortic arterial segment } \\
\text { above comparative values }\end{array}$ & All & Men & Women \\
\hline Carotid artery & $35(21)$ & $9(10)$ & $26(35)$ \\
Subclavian artery & $90(55)$ & $51(57)$ & $39(53)$ \\
Iliac artery & $73(54)$ & $37(51)$ & $36(56)$ \\
Femoral artery & $78(57)$ & $36(49)$ & $42(66)$ \\
\hline
\end{tabular}

level of the iliac arteries. Furthermore, $35 \%$ of patients who suffered from type A or type B dissection underwent intervention of a nonaortic arterial segment at some point.

Although interventions on the subclavian arteries are frequent, these are mostly due to aneurysms without previous dissection. In patients with a dissection extending into the iliac arteries, $48 \%$ needed some form of intervention initially or during follow-up. The overall need for subsequent interventions in dissected, nonaortic arterial segments was $32 \%$. Yetman and colleagues published their observation of peripheral aneurysms in patients with MFS and showed that dissection occurred in 32 of the $47(68 \%)$ peripheral aneurysms they observed. ${ }^{9}$ In their population, 13 of the $44(30 \%)$ patients sought emergent care for symptomatic distal dissection. Interestingly, none of the patients in this cohort of 13

TABLE 4. Number of dissected nonaortic arterial segments with numbers and percentages of patients including the numbers and percentages of interventions

\begin{tabular}{|c|c|c|c|c|}
\hline \multirow[b]{2}{*}{$\begin{array}{l}\text { Dissection in nonaortic } \\
\text { arterial segment }\end{array}$} & \multicolumn{2}{|c|}{$\begin{array}{c}\text { Dissected arterial } \\
\text { segments }\end{array}$} & \multicolumn{2}{|c|}{$\begin{array}{c}\text { Intervened arterial } \\
\text { segments }\end{array}$} \\
\hline & $\mathbf{n}$ & $\begin{array}{l}\text { Patients, } \\
\text { n }(\%)\end{array}$ & $\mathbf{n}$ & $\begin{array}{l}\text { Patients, } \\
\text { n (\%) }\end{array}$ \\
\hline Total & 66 & $33(33)$ & 21 & $14(14)$ \\
\hline Innominate artery & 7 & $7(7)$ & 0 & $0(0)$ \\
\hline Carotid artery & 5 & $5(5)$ & 1 & $1(1)$ \\
\hline Subclavian artery & 12 & $10(10)$ & 1 & $1(1)$ \\
\hline Iliac artery & 40 & $28(28)$ & 19 & $14(14)$ \\
\hline Femoral artery & 2 & $1(1)$ & 0 & $0(0)$ \\
\hline
\end{tabular}


TABLE 5. Interventions in nonaortic arterial segments in patients with MFS

\begin{tabular}{|c|c|c|c|}
\hline $\begin{array}{c}\text { Nonaortic } \\
\text { arterial segment }\end{array}$ & $\begin{array}{l}\text { Interventions, } \\
\text { n (patient } \mathbf{n} \text { ) }\end{array}$ & $\begin{array}{l}\text { Intervened } \\
\text { segments, } \mathrm{n}\end{array}$ & Type of intervention \\
\hline Innominate artery & $1(1)$ & 1 & Symptomatic aneurysm repair via graft replacement without previous dissection \\
\hline \multirow[t]{2}{*}{ Carotid artery } & $2(2)$ & 2 & $\mathrm{n}=1$ open fenestration during aortic repair \\
\hline & & & $\mathrm{n}=1$ symptomatic aneurysm repair via graft replacement without previous dissection \\
\hline \multirow[t]{5}{*}{ Subclavian artery } & $7(4)$ & 7 & $\mathrm{n}=2$ carotid-subclavian bypasses \\
\hline & & & $\mathrm{n}=3$ interposition grafts \\
\hline & & & $\mathrm{n}=1$ ligation during arch repair \\
\hline & & & $\mathrm{n}=1$ reintervention, bypass after ligation \\
\hline & & & $\mathrm{n}=5$ of 6 aneurysms without previous dissection \\
\hline \multirow[t]{5}{*}{ Iliac artery } & $19(16)$ & 29 & $\mathrm{n}=4$ iliac artery graft replacements during TAAAR \\
\hline & & & $\mathrm{n}=9$ Y-graft \\
\hline & & & $\mathrm{n}=1$ isolated open aneurysm repair \\
\hline & & & Acute dissection repair, $\mathrm{n}=1$ fenestration/stenting, $\mathrm{n}=1$ Y-graft \\
\hline & & & Reintervention, $\mathrm{n}=2$ anastomotic aneurysm, $\mathrm{n}=1$ Y-graft after fenestration/stenting \\
\hline Visceral artery & $2(2)$ & 2 & $\mathrm{n}=2$ splenic artery coilings \\
\hline Intercostal artery & $3(1)$ & 3 & $\mathrm{n}=3$ intercostal artery coilings \\
\hline
\end{tabular}

TAAAR, Thoracoabdominal aortic aneurysm repair.

patients had already undergone aortic root surgery. This is in contrast to our study in which all patients with peripheral artery dissections had already suffered from Stanford type A or type B dissection.

In a study by Mariucci and colleagues, ${ }^{10} 43 \%$ of iliac arteries were dilated, whereas $88 \%$ were dilated in the current study. This difference can be explained because Mariucci and colleagues ${ }^{10}$ excluded patients with previous dissections, which drives the need for interventions in our patient population. Average diameters of the carotid and subclavian arteries in the Italian study were within the same range as we have observed. Average diameters of

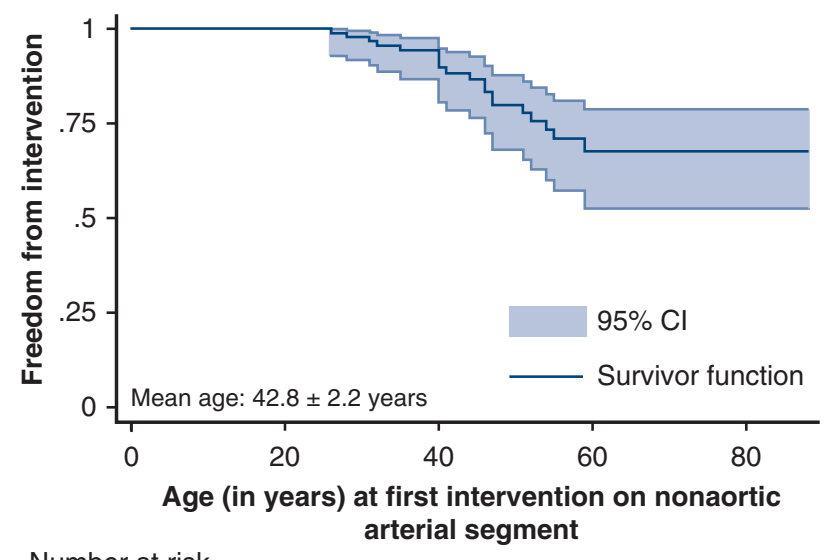

Number at risk

$\begin{array}{lllll}100 & 100 & 63 & 18 & 2\end{array}$

FIGURE 2. Kaplan-Meier graph depicting age at first nonaortic arterial segment intervention in patients with Marfan syndrome. $C I$, Confidence interval. the iliac arteries were larger in our population, because of the reasons explained previously.

Aneurysms in nonaortic arterial segments are quite common in other connective tissue disorders such as Loeys-Dietz syndrome and the vascular type of Ehlers-Danlos syndrome. Although MFS is much more common, little attention has been directed toward changes in these nonaortic arterial segments. In our cohort, $61 \%$ of the 414 measured points of interest were dilated (ie, had diameters above the upper range of normal). In the report by Yetman and colleagues, ${ }^{9} 31 \%$ of patients presented with peripheral artery aneurysm whereas a smaller study has recently reported on a group of 10 of 15

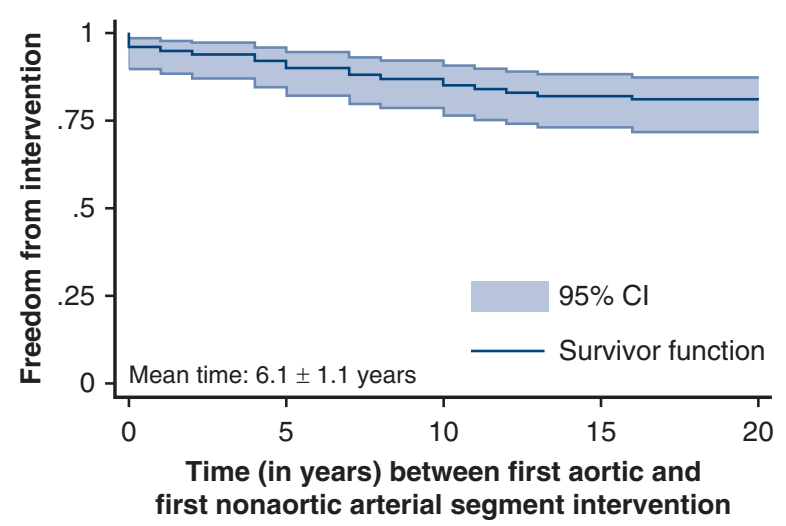
Number at risk
100
92
87
82
81

FIGURE 3. Kaplan-Meier graph depicting time between first aortic and first nonaortic arterial segment intervention in patients with Marfan syndrome. $C I$, Confidence interval. 


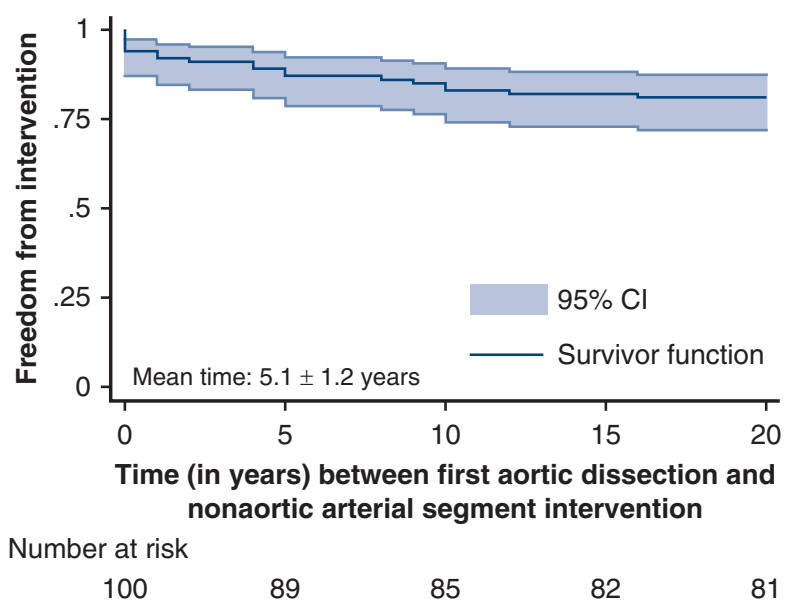

FIGURE 4. Kaplan-Meier graph depicting time between first dissection and nonaortic arterial segment intervention in patients with Marfan syndrome. $\mathrm{CI}$, Confidence interval.

patients with MFS who had peripheral aneurysms. ${ }^{11}$ Although it is debatable what kind of criteria regarding normal vessel diameters can be applied to patients with MFS, the current data highlights the clinical significance, because $19 \%$ of patients needed at least 1 intervention on a nonaortic arterial segment. When plotting the diameter increase over time in nonaortic arterial segments in patients who eventually underwent intervention, the increase is remarkably linear. This essentially means that young patients with MFS who show some growth in nonaortic arterial segments have a high likelihood to need intervention in this segment at some point during follow-up, especially if they had already suffered from acute dissection.

More than half of the interventions were performed on the level of the iliac arteries and most $(88 \%)$ had suffered from previous dissection. Because $16 \%$ of MFS patients had an iliac artery intervention during follow-up, the pelvis should be included in routine imaging of the aorta in these patients. Because we saw a number of patients who needed interventions on the supra-aortic branches without previous dissection, we also recommend routine imaging in patients without previous dissection, although the prevalence was not as high as in the study by Gaertner and colleagues in which 6 of 15 patients with MFS presented with aneurysms of the supra-aortic branches. ${ }^{11}$

Regular imaging of the aorta and its branches is recommended. Screening should be continued until the growth rate is established. Thresholds for intervention depend on etiology, location, growth rate, aneurysm morphology, and many other patient-specific factors. As a general rule, we operate on peripheral arterial aneurysms in patients with MFS when they reach a diameter of 2.5 to $3.0 \mathrm{~cm}$. In our patient population $20 \%$ of patients with MFS needed some form of intervention on nonaortic arterial segments 5 to 6 years after their first aortic intervention, referring to the first aortic dissection of the

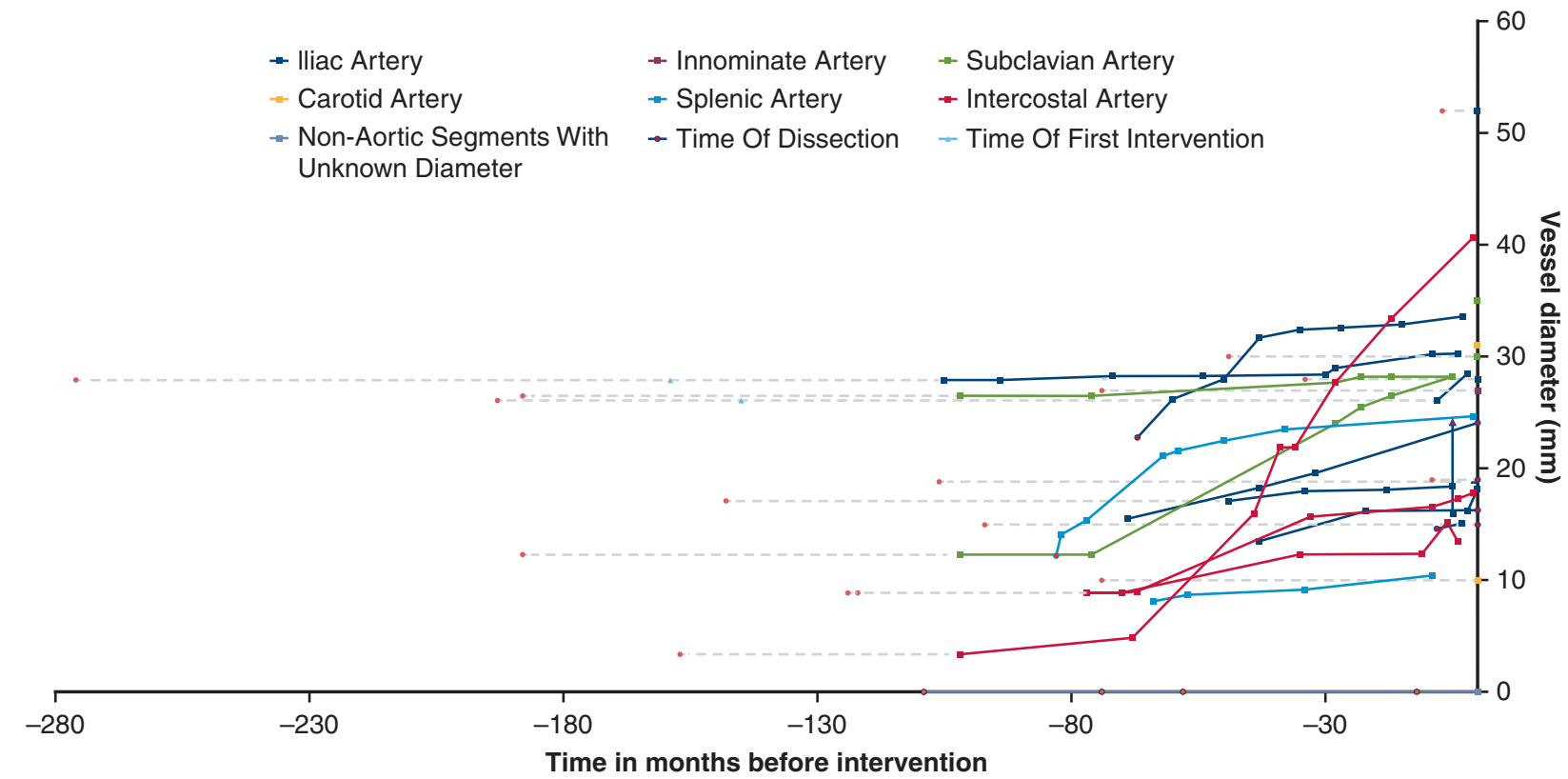

FIGURE 5. Diameter increase of every nonaortic arterial segment that was intervened at some point: point 0 corresponds to time of intervention. Every line is 1 nonaortic arterial segment leading up to the intervention. Gray lines denote unknown diameters. A red dot and a triangle mark aortic events. A red dot stands for aortic dissection and the triangle for the first nonaortic intervention. Patients with unknown diameters at the time of intervention are shown as a black line. These are mostly patients in whom the preinterventional diameter could not be independently assessed because the imaging was done many years ago in outside hospitals and original imaging data were no longer available. 

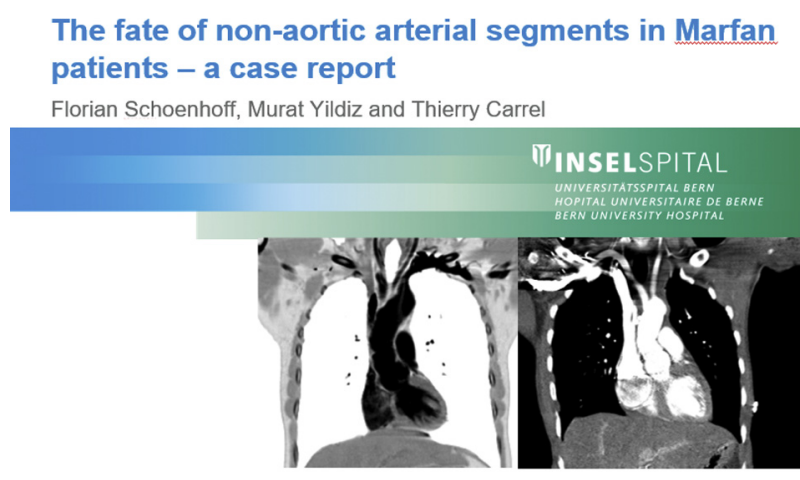

Department of Cardiovascular Surgery, University Hospital Berne, Switzerland

VIDEO 1. This video shows the fate of nonaortic aneurysms in one of our patients in our series. Video available at: https://www.jtcvs.org/article/ S0022-5223(18)32863-0/fulltext.

patient if the patient had a history of dissection (Figures 3 and 4).

\section{Strengths and Limitations}

Very few data on diameters of nonaortic arterial segments in patients with MFS are available. Most articles only report true aneurysms that underwent intervention at some point. There is no series that systematically measured diameters throughout the entire cohort. Although our follow-up is quite strong, not all patients always received a CT or magnetic resonance imaging scan that included all arterial segments. Because of these missing values, it was not possible to calculate the true growth rate of the arterial segments. Our study population includes only MFS patients who had undergone aortic surgery at some point, which might be a bias toward a more severe phenotype in general.

\section{CONCLUSIONS}

Most patients with MFS included in our study had at least 2 dilated nonaortic arterial segments. One-fifth of patients with MFS needed to undergo interventions on nonaortic arterial segments 5 to 6 years after their first aortic intervention or dissection. Most interventions occurred on the level of the iliac arteries after dissection and less frequently on the subclavian arteries because of aneurysms without previous dissection. Routine long-term follow-up imaging should include the iliac arteries as well as the supra-aortic branches. We recommend annual follow-up when the diameter of a nonaortic arterial segment has reached a diameter of $2.0 \mathrm{~cm}$.

\section{Conflict of Interest Statement}

Thierry Carrel received financial funds outside the submitted work from Xeltis AG, Zurich, Switzerland. All other authors have nothing to disclose with regard to commercial support.

\section{References}

1. Judge DP, Dietz HC. Marfan's syndrome. Lancet. 2005;366:1965-76.

2. Faivre L, Collod-Beroud G, Loeys BL, Child A, Binquet C, Gautier E, et al. Effect of mutation type and location on clinical outcome in 1,013 probands with Marfan syndrome or related phenotypes and FBN1 mutations: an international study. Am J Hum Genet. 2007;81:454-66.

3. Dietz HC, Cutting GR, Pyeritz RE, Maslen CL, Sakai LY, Corson GM, et al. Marfan syndrome caused by a recurrent de novo missense mutation in the fibrillin gene. Nature. 1991;352:337-9.

4. Loeys BL, Dietz HC, Braverman AC, Callewaert BL, De Backer J, Devereux RB, et al. The revised Ghent nosology for the Marfan syndrome. J Med Genet. 2010; 47:476-85.

5. Johnston KW, Rutherford RB, Tilson MD, Shah DM, Hollier L, Stanley JC. Suggested standards for reporting on arterial aneurysms. Subcommittee on reporting standards for arterial aneurysms, ad hoc committee on reporting standards, Society for Vascular Surgery and North American Chapter, International Society for Cardiovascular Surgery. J Vasc Surg. 1991;13:452-8.

6. Thrush A, Hartshorne T. Peripheral Vascular Ultrasound: How, Why, and When. London: Churchill Livingstone; 2004.

7. Engelfriet PM, Boersma E, Tijssen JG, Bouma BJ, Mulder BJ. Beyond the root: dilatation of the distal aorta in Marfan's syndrome. Heart. 2006;92: 1238-43.

8. Schoenhoff FS, Jungi S, Czerny M, Roost E, Reineke D, Matyas G, et al. Acute aortic dissection determines the fate of initially untreated aortic segments in Marfan syndrome. Circulation. 2013;127:1569-75.

9. Yetman AT, Roosevelt GE, Veit N, Everitt MD. Distal aortic and peripheral arterial aneurysms in patients with Marfan syndrome. J Am Coll Cardiol. 2011;58:2544-5.

10. Mariucci EM, Lovato L, Rosati M, Palena LM, Bonvicini M, Fattori R. Dilation of peripheral vessels in Marfan syndrome: importance of thoracoabdominal MR angiography. Int J Cardiol. 2013;167:2928-31.

11. Gaertner S, Alembik Y, Cordeanu EM, Dollfus H, Lejay A, Chakfe N, et al. Should we systematically screen for peripheral arterial aneurysms in all patients with Marfan syndrome? Int J Cardiol. 2014;172:e94-5.

Key Words: aortic surgery, Marfan syndrome, connective tissue disease 